\title{
Anti-citrullinated protein antibodies contribute to platelet activation in rheumatoid arthritis
}

\author{
Kim L.L. Habets ${ }^{1 *}$, Leendert A. Trouw ${ }^{1}$, E.W. Nivine Levarht ${ }^{1}$, Suzanne J.A. Korporaal ${ }^{2,3}$, Petra A.M. Habets ${ }^{4}$,
} Philip de Groot ${ }^{2}$, Tom W.J. Huizinga ${ }^{1}$ and René E.M. Toes ${ }^{1}$

\begin{abstract}
Introduction: Although the role of platelets in rheumatoid arthritis (RA) is relatively unexplored, recent studies point towards a contribution of platelets in arthritis. We set out to determine platelet phenotype in RA and studied whether this could be influenced by the presence of anti-citrullinated protein antibodies (ACPA).

Methods: Platelets from healthy controls were incubated in the presence of plasma of patients with RA or age- and sex-matched healthy controls and plasma from ACPA ${ }^{\text {neg }}$ or ACPA ${ }^{\text {pos }}$ patients or in the presence of plate-bound ACPA. Characteristics of platelets isolated from patients with RA were correlated to disease activity.

Results: Platelets isolated from healthy controls displayed markers of platelet activation in the presence of plasma derived from RA patients, as determined by P-selectin expression, formation of aggregates and secretion of soluble CD40 ligand (sCD40L). Furthermore, levels of P-selectin expression and SCD40L release correlated with high ACPA titres. In accordance with these findings, enhanced platelet activation was observed after incubation with ACPA ${ }^{\text {pos }}$ plasma versus ACPA ${ }^{\text {neg }}$ plasma. Pre-incubation of platelets with blocking antibodies directed against low-affinity immunoglobulin $\mathrm{G}$ receptor (FcyRlla) completely inhibited the ACPA-mediated activation. In addition, expression of P-selectin measured as number of platelets correlated with Disease Activity Score in 44 joints, C-reactive protein level, ACPA status and ACPA level.

Conclusions: We show for the first time that ACPA can mediate an FcyRlla-dependent activation of platelets. As ACPA can be detected several years before RA disease onset and activated platelets contribute to vascular permeability, these data implicate a possible role for ACPA-mediated activation of platelets in arthritis onset.
\end{abstract}

\section{Introduction}

Most studies addressing the contribution of the immune system in rheumatoid arthritis (RA) have been focused on white blood cells and antibodies, but the potential role of platelets has received little attention. Although our classical perception of platelets is that of key players in haemostasis and thrombosis, several lines of evidence suggest that platelets also mediate inflammatory processes [1-3]. Platelets carry various mediators facilitating the recruitment of circulating monocytes and/or leucocytes to the injured endothelium and have the potential to propagate vascular permeability and chronic inflammation of the vessel wall [4-6]. Activated platelets are

\footnotetext{
* Correspondence: k.l.I.habets@lumc.nl

'Department of Rheumatology, Leiden University Medical Centre, C1-R, PO Box 9600, 2300 RC, Leiden, the Netherlands

Full list of author information is available at the end of the article
}

characterised by surface expression of P-selectin (CD62P) and produce both membrane-bound and soluble CD40 ligand (sCD40L). Platelet-derived sCD40L acts as a trigger for the activation and inflammation of the endothelium as it increases the expression of inflammatory adhesion receptors (vascular cell adhesion molecule 1 and intracellular adhesion molecule 1), the production of chemokines (monocyte chemoattractant protein 1, interleukin [IL]-6 and IL-8) and the production of matrix metalloproteinase $9[7,8]$.

RA is characterised by inflammation with progressive destruction of the synovial joints and physical disability [9]. A complex network of small blood vessels is present beneath the surface of the synovium, and enhanced synovial vascularity and biomarkers of angiogenesis have been described in different chronic arthritic diseases [10]. Initially, platelet activation within the joints has 
been described in mice where platelet depletion resulted in reduced vascular leakage in arthritic joints and attenuated inflammatory arthritis $[4,11,12]$. More recently, it became apparent that such mechanisms might also be present in patients with RA, as increased numbers of platelets and platelet-derived proteins within the synovium and synovial fluid have been observed [11, 13-15]. Furthermore, enhanced levels of soluble P-selectin and sCD40L present in serum and/or plasma correlate with RA activity and suggest potential platelet activity in vivo [16-19]. Importantly, the risk of deep vein thrombosis and pulmonary embolism is increased in patients with RA [20, 21]. However, the mechanism contributing to the putative elevated platelet activity in RA is not known. Because platelets express the low-affinity immunoglobulin G (IgG) receptor (FcrRIIa), and because of the importance of autoantibodies on the thrombotic risk in systemic lupus erythematosus, we propose a role for anti-citrullinated protein antibodies (ACPA) in the activation of platelets [22]. These autoantibodies recognise a group of autoantigens which are post-translationally modified by peptidyl arginine deaminase (PAD) enzymes, leading to the conversion of an arginine to citrulline. ACPA are highly specific for RA and recognise various citrullinated antigens, such as fibrinogen, vimentin, collagen type II and enolase. Typically, 50-70 \% of patients with RA are $\mathrm{ACPA}^{\text {pos }}$, and, of more importance, ACPA can be observed several years before the onset of disease. The presence of ACPA is predictive of a more severe disease course, which necessitates a more aggressive treatment regimen [23-25]. Furthermore, patients with RA have an increased cardiovascular risk, owing mainly to atherosclerotic lesion formation. Intriguingly, the augmented cardiovascular burden in patients with RA is independent of the presence of traditional cardiovascular risk factors such as dyslipidaemia, hypertension, smoking and physical inactivity, but it is associated with the presence of rheumatoid factor (RF)-IgM and ACPA [26-34]. In the present study, we show for the first time an activating interplay between platelets and ACPA. Because of the prominent role of platelets during endothelial dysfunction and vascular permeability that may lead to enhanced vascular leakage in the joints, this interplay could potentially contribute to the increased cardiovascular risk and RA disease burden observed in $\mathrm{ACPA}^{\text {pos }}$ patients.

\section{Methods}

\section{Patient characteristics}

Samples were obtained from patients with RA (both $\mathrm{ACPA}^{\text {pos }}$ and $\mathrm{ACPA}^{\text {neg }}$ ) who visited the outpatient clinic of the Department of Rheumatology at Leiden University Medical Centre, Leiden, the Netherlands. Patients fulfilled the 1987 criteria for RA [35] at the time of diagnosis and gave us their written informed consent for sample acquisition. Treatment included a wide variety of disease-modifying antirheumatic drugs (DMARDs), biologic agents and glucocorticoids. Peripheral blood for platelet isolation was collected from 32 patients with RA (Disease Activity Score in 44 joints [DAS44] $2.1 \pm 0.2)$. Of these patients, $78 \%$ were $\mathrm{ACPA}^{\text {pos }}$ (median ACPA $515 \mathrm{AU} / \mathrm{ml}$, interquartile range [IQR] 267.5-2013). For the experiments with plasma samples, healthy platelets were incubated in the presence of plasma of patients with RA. To ensure active disease, only plasma samples from patients with DAS44 > 2.4 were included (DAS44 $2.7 \pm 0.05$ ). In the first cohort, plasma samples from age-matched $(62.4 \pm 2.1$ vs $61.2 \pm 0.8)$ and sex-matched healthy volunteers were used as a control. In the second cohort, plasma from $\mathrm{ACPA}^{\text {neg }}$ (ACPA $\left.8.8 \pm 1.6 \mathrm{AU} / \mathrm{ml}\right)$ and $\mathrm{ACPA}^{\text {pos }}(\mathrm{ACPA}$ $664.6 \pm 137.9)$ patients with RA was used, and samples were matched for age $(56.0 \pm 2.8$ vs $55.6 \pm 2.6)$, sex and DAS44 score $(3.1 \pm 0.8$ vs $3.24 \pm 0.1)$. Permission for conduct of the study was obtained from the ethical review board of Leiden University Medical Centre. The characteristics of plasma cohorts 1 and 2 are depicted in Table 1.

\section{Platelet isolation}

Platelets were isolated from fresh buffy coats or from freshly drawn venous blood obtained from healthy control subjects or patients with RA and then collected into citrate-containing blood tubes. Platelets were isolated as described elsewhere [36]. Platelet-rich plasma was prepared by centrifugation $\left(156 \times g, 15 \mathrm{~min}, 20^{\circ} \mathrm{C}\right)$. Next, a 0.1 vol of acid-citrate-dextrose $(2.5 \%$ trisodium citrate, $1.5 \%$ citric acid, $2 \%$ D-glucose) was added to lower the $\mathrm{pH}$ of the plasma to 6.5, preventing activation during further isolation. Subsequently, platelets were purified by centrifugation $\left(330 \times g, 15 \mathrm{~min}, 20^{\circ} \mathrm{C}\right)$, and the platelet pellet was resuspended in HEPES-buffered Tyrode's solution $\left(145 \mathrm{mM} \mathrm{NaCl}, 5 \mathrm{mM} \mathrm{KCl}, 0.5 \mathrm{mM} \mathrm{Na}_{2} \mathrm{HPO}_{4}\right.$, $1 \mathrm{mM} \mathrm{MgSO}_{4}, 10 \mathrm{mM}$ 2-[4-(2-hydroxyethyl)piperazin1-yl] ethanesulfonic acid [HEPES], pH 6.5) containing $5 \mathrm{mmol} / \mathrm{L}$ D-glucose. Prostaglandin $\mathrm{I}_{2}$ (Cayman Chemical, Ann Arbor, MI, USA) was added to a final concentration of $10 \mathrm{ng} / \mathrm{ml}$. Next, the washing procedure was repeated, but now the platelet pellet was resuspended in HEPESbuffered Tyrode's solution, pH 7.2, containing $5 \mathrm{mmol} / \mathrm{L}$ D-glucose to a final concentration of $2 \times 10^{8}$ platelets $/ \mathrm{ml}$. Before the experiments, platelets were left at room temperature (RT) for at least 30 minutes to ensure a resting state. Mean platelet volume (MPV), platelet distribution width (PDW) and platelet concentration were determined within $2 \mathrm{~h}$ from blood collection to minimise the effect of platelet swelling upon storage (Sysmex KX-21N automated haematology analyser; Sysmex, Kobe, Japan). 
Table 1 Characteristics of plasma cohorts 1 and 2

\begin{tabular}{|c|c|c|c|}
\hline Plasma cohort 1 & Healthy subjects & Patients with RA & $P$ value \\
\hline Female, n (\%) & $33(78.6)$ & $36(81.8)$ & ns \\
\hline Male, n (\%) & $9(21.4)$ & $8(18.2)$ & ns \\
\hline Age, yr (mean \pm SEM) & $60.9 \pm 0.8$ & $61.83 \pm 2.1$ & ns \\
\hline TNF-a, pg/ml (median [IQR]) & $75.0[51.4-88.9]$ & $87.8[57.8-126.4]$ & 0.0235 \\
\hline $\mathrm{PAF}, \mathrm{ng} / \mathrm{ml}$ (mean $\pm \mathrm{SEM})$ & $27.9 \pm 1.4$ & $33.4 \pm 1.7$ & 0.0185 \\
\hline Plasma cohort 2 & ACPA $^{\text {neg }}$ patients with RA & $\mathrm{ACPA}^{\mathrm{pos}}$ patients with RA & $P$ value \\
\hline Female, n (\%) & $26(78.8)$ & $25(75.8)$ & ns \\
\hline Male, n (\%) & $7(21.2)$ & $8(24.2)$ & ns \\
\hline Age, yr (mean \pm SEM) & $56.0 \pm 2.8$ & $55.6 \pm 2.6$ & ns \\
\hline DAS44 (mean \pm SEM) & $3.1 \pm 0.8$ & $3.2 \pm 0.1$ & ns \\
\hline ACPA (AU/ml) (median [IQR]) & $6.2[2.6-14.6]$ & $238.7[98.4-1093]$ & 0.0001 \\
\hline RF IgM (median [IQR]) & $1.0[0.0-2.5]$ & $23.0[6.0-80.0]$ & 0.0001 \\
\hline TNF-a, pg/ml (mean \pm SEM) & $62.8 \pm 8.8$ & $77.6 \pm 6.1$ & ns \\
\hline $\mathrm{PAF}, \mathrm{ng} / \mathrm{ml}$ (mean $\pm \mathrm{SEM})$ & $146.1 \pm 11.5$ & $120.9 \pm 9.7$ & ns \\
\hline
\end{tabular}

$A C P A$ anti-citrullinated protein antibodies, DAS44 Disease Activity Score in 44 joints, IgM immunoglobulin M, IQR interquartile range, $n s$ not significant, $P A F$ platelet-activating factor, $R A$ rheumatoid arthritis, $R F$ rheumatoid factor, $T N F$ tumour necrosis factor

\section{Platelet incubation in the presence of plasma}

Platelets were isolated from fresh buffy coats $\left(2 \times 10^{8}\right.$ platelets $/ \mathrm{ml}$ ) and incubated for 90 minutes at $37{ }^{\circ} \mathrm{C}$ in the presence of diluted plasma (final dilution 1:6). Next, platelets were centrifuged $\left(330 \times g, 15 \mathrm{~min}, 20^{\circ} \mathrm{C}\right)$, and then supernatants were collected and stored at $-20{ }^{\circ} \mathrm{C}$ until further analysis. Platelet activation was determined by flow cytometry to measure the expression of P-selectin and the presence of platelet aggregates. Furthermore, the production of sCD40L was determined using an enzyme-linked immunosorbent assay (ELISA; eBioscience, San Diego, CA, USA) according to the manufacturer's protocol. When applicable, change in SCD40L was calculated to correct for the presence of sCD40L in plasma.

\section{Flow cytometry}

To determine P-selectin expression on platelets, platelets were stained with CD62P phycoerythrin (clone AK-4; BD Biosciences, San Jose, CA, USA) diluted in HEPESbuffered Tyrode's solution, pH 7.2 (1:40 dilution), and incubated for 20 minutes at RT, after which cells were fixed using $1 \%$ paraformaldehyde (no wash) and analysed by flow cytometry (FACSCalibur; BD Biosciences). Analysis was performed using FACSDiva software (BD Biosciences) and FlowJo software (Tree Star, Ashland, OR, USA). Aggregate analysis was based on the appearance of a larger population in the forward scatter (FSC) and side scatter (SSC) after stimulation as described by Matzdorff et al. [37] (Additional file 1: Figure S1). For this experiment, the purity of platelets was determined using CD41 (>95\%), and the position of the platelet aggregate population was determined by activating platelets with $5 \mu \mathrm{M}$ thrombin receptor-activating peptide. Next, CD62P expression of the aggregated and nonaggregated platelets was determined (Additional file 1: Figure S1a). We observed a nice correlation (Pearson's $r=0.5130 ; P<0.0001)$ between the percentage of aggregates and $\mathrm{P}$-selectin expression, both determined by flow cytometry after incubation in the presence of plasma samples from cohort 1 (control subjects and patients with RA), validating our method of detecting aggregates (Additional file 1: Figure S1b).

\section{ACPA purification using CCP2-coated beads}

ACPA-IgG and ACPA-depleted IgG were purified from plasma of patients with RA by antigen affinity chromatography using cyclic citrullinated peptide 2 (CCP2)coated beads (Pierce Biotechnology/Thermo Scientific, Rockford, IL, USA). The latter were prepared by mixing $500 \mu \mathrm{l}$ of biotinylated CCP2 dissolved in phosphatebuffered saline (PBS) at $1 \mathrm{mg} / \mathrm{ml}$ with $5 \mathrm{ml}$ of Pierce NeutrAvidin Plus UltraLink slurry resin (Thermo Scientific) for $1 \mathrm{~h}$ at RT. Following extensive washing with PBS, the CCP2-coated beads were dissolved in PBS to reach a total volume of $7.5 \mathrm{ml}$, and $75 \mu \mathrm{l}$ of bead solution were loaded into each well of a 96-well filter plate (OF 1100; Orochem Technologies, Naperville, IL, USA). Plasma samples (diluted 1:5 in PBS) were applied on beads, and ACPA binding to CCP2 was allowed by vortexing the plate at $600 \mathrm{rpm}$ for $2 \mathrm{~h}$ at RT. The plate was then centrifuged for 2 minutes at $500 \times g$, and the flow-through was collected in 
a 96-well deep-well storage plate (Pierce Biotechnology/ Thermo Scientific). Beads were then washed sequentially twice with $150 \mu \mathrm{l}$ of PBS and once with $25 \mathrm{mM}$ ammonium bicarbonate. Of note, the first washing of the beads was combined with the flow-through. ACPA elution was performed by twice adding $150 \mu \mathrm{l}$ of $100 \mathrm{mM}$ formic acid at $\mathrm{pH} 2.5$ to the beads. The elution fraction was immediately neutralised with $2 \mathrm{M}$ Tris buffer. ACPA-depleted IgG (flow-through) and eluted ACPA-IgG were further analysed by ELISA. ACPA percentages were calculated by setting total IgG (flow-through + elution) at $100 \%$.

\section{Measurement of IgG-ACPA}

Plasma samples were assessed for the presence of IgGACPA by ELISA based on reactivity against CCP2 (Euro Diagnostica, Nijmegen, the Netherlands). Plasma samples were tested at a 1:50 dilution or higher according to the manufacturer's instructions, using rabbit anti-human IgG-horseradish peroxidase (Dako, Heverlee, Belgium) and 2,2'-azinobis(3-ethylbenzthiazoline-6-sulfonic acid) (Sigma-Aldrich, Zwijndrecht, Belgium).

\section{ACPA-mediated activation of platelets}

Plates were coated overnight with streptavidin $(25 \mu \mathrm{g} / \mathrm{ml})$ and subsequently incubated for $1 \mathrm{~h}$ at $37^{\circ} \mathrm{C}$ with biotinylated citrulline- and arginine-containing peptides $(1 \mu \mathrm{g} / \mathrm{ml})$. Plates were then incubated with $\mathrm{ACPA}^{\text {pos }}$ or $\mathrm{ACPA}^{\text {neg }}$ plasma (1:5 dilution in PBS $+0.1 \%$ bovine serum albumin) at $37{ }^{\circ} \mathrm{C}$ for $1 \mathrm{~h}$. After extensive washing of the coated plates, platelets isolated from healthy volunteers were incubated for $2 \mathrm{~h}$ at $37{ }^{\circ} \mathrm{C}$, after which supernatants were collected by centrifugation $\left(330 \times g, 15 \mathrm{~min}, 20^{\circ} \mathrm{C}\right)$ and platelets were resuspended for staining for fluorescenceactivated cell sorting analysis. In FcyRIIa blocking experiments, platelets were pre-incubated with anti-CD32 (clone IV.3; STEMCELL Technologies, Vancouver, BC, Canada) or isotype control (mouse IgG2b; eBioscience) for $1 \mathrm{~h}$ at $37{ }^{\circ} \mathrm{C}$. ACPA binding to the plates was confirmed by standard ELISA in separate coated wells (data not shown). All experiments were performed in triplicates. The ratio was calculated by dividing the percentage of $\mathrm{CD} 62 \mathrm{P}^{\mathrm{pos}}$ platelets in the presence of citrulline-containing peptides by the percentage of $\mathrm{CD} 62 \mathrm{P}^{\mathrm{pos}}$ platelets in the presence of arginine-containing peptides.

\section{Statistical analysis}

Normality testing was performed using the KolmogorovSmirnov test (with the Dallal-Wilkinson-Lilliefor correction for $P$ value). For normally distributed populations, mean \pm standard deviation values are depicted (unless stated otherwise) and Student's $t$ test was used. For nonnormally distributed populations, the median and IQR are depicted and significance was determined using the Mann-Whitney $U$ test or the corresponding analysis of variance when multiple groups were compared. Correlations were determined using the Pearson's $r$ correlation coefficient, as all populations tested were normally distributed. Linear regression analyses were performed with group (group 1 = control subjects, group $2=$ patients with RA) as the independent variable and CD62P aggregates, and $\mathrm{sCD} 40 \mathrm{~L}$ as dependent variables. To test for paired samples, the Wilcoxon matched pairs test was used. Fisher's exact test was used to determine the differences between sexes in the two groups. Data were analysed using GraphPad Prism version 5.0 software (GraphPad Software, La Jolla, CA, USA). Linear regression analyses were performed using STATA version 12 software (StataCorp, College Station, TX, USA).

\section{Results}

\section{Plasma derived factors from patients with RA increase} platelet activity

As described, patients with RA display a more activated platelet phenotype, but the underlying mechanism is not clear. To investigate if plasma-derived factors could have contributed to this observation, we incubated freshly isolated platelets from healthy volunteers with plasma obtained from patients with RA. To ensure moderate to high disease activity, only plasma of patients with a DAS44 $>2.4$ were included. Plasma from age- and sex-matched healthy volunteers was used as a control (cohort 1 ). Increased expression of P-selectin $(21.6 \pm 0.5 \%$ vs $24.4 \pm 0.6 \%$; $P<0.001)$ (Fig. 1a), increased P-selectin mean fluorescence intensity (MFI) $(119.5 \pm 1.5$ vs $130.5 \pm 2.0 ; P<0.0001)$ (Fig. $1 b)$, more platelet aggregation $(3.3 \pm 0.1$ vs. $3.9 \pm 0.2 ; P<0.01)$ (Fig. $1 \mathrm{~d}$ ) and enhanced production of sCD40L $(0.99 \pm 0.0 .14 \mathrm{ng} / \mathrm{ml}$ vs $1.5 \pm 0.18 \mathrm{ng} / \mathrm{ml} ; P<0.05$ ) (Fig. 1f) were detected after incubation of platelets of healthy subjects in the presence of plasma from patients with RA. Notably, linear regression analysis indicated that platelet characteristics such as P-selectin expression, aggregate formation and the production of sCD40L induced by a given plasma sample predicted group in the plasma donor (control vs patients with RA) (Table 2).

Next, we studied which factors in plasma could be responsible for the observed platelet activity. Plateletactivating factor (PAF) is a potent inflammatory phospholipid implicated in the release of various cytokines involved in RA, such as tumour necrosis factor (TNF)- $\alpha$, IL-1 and IL-6. In addition, TNF- $\alpha$ is able to activate platelets through stimulation of the arachidonic acid pathway [38]. Therefore, we determined TNF- $\alpha$ and PAF levels in the plasma samples used. We did observe higher TNF- $\alpha$ levels in the plasma of patients with RA (median $87.8 \mathrm{pg} / \mathrm{ml}$, IQR 57.8-126.4)than in controls (median $75.0 \mathrm{pg} / \mathrm{ml}$, IQR 51.4-88.9) $(P<0.05)$ and increased levels of PAF (RA $33.4 \pm 1.7 \mathrm{ng} / \mathrm{ml}$ vs controls $27.9 \pm 1.4 \mathrm{ng} / \mathrm{ml} ; P<0.05$ ) (data not shown). However, we could not find a 


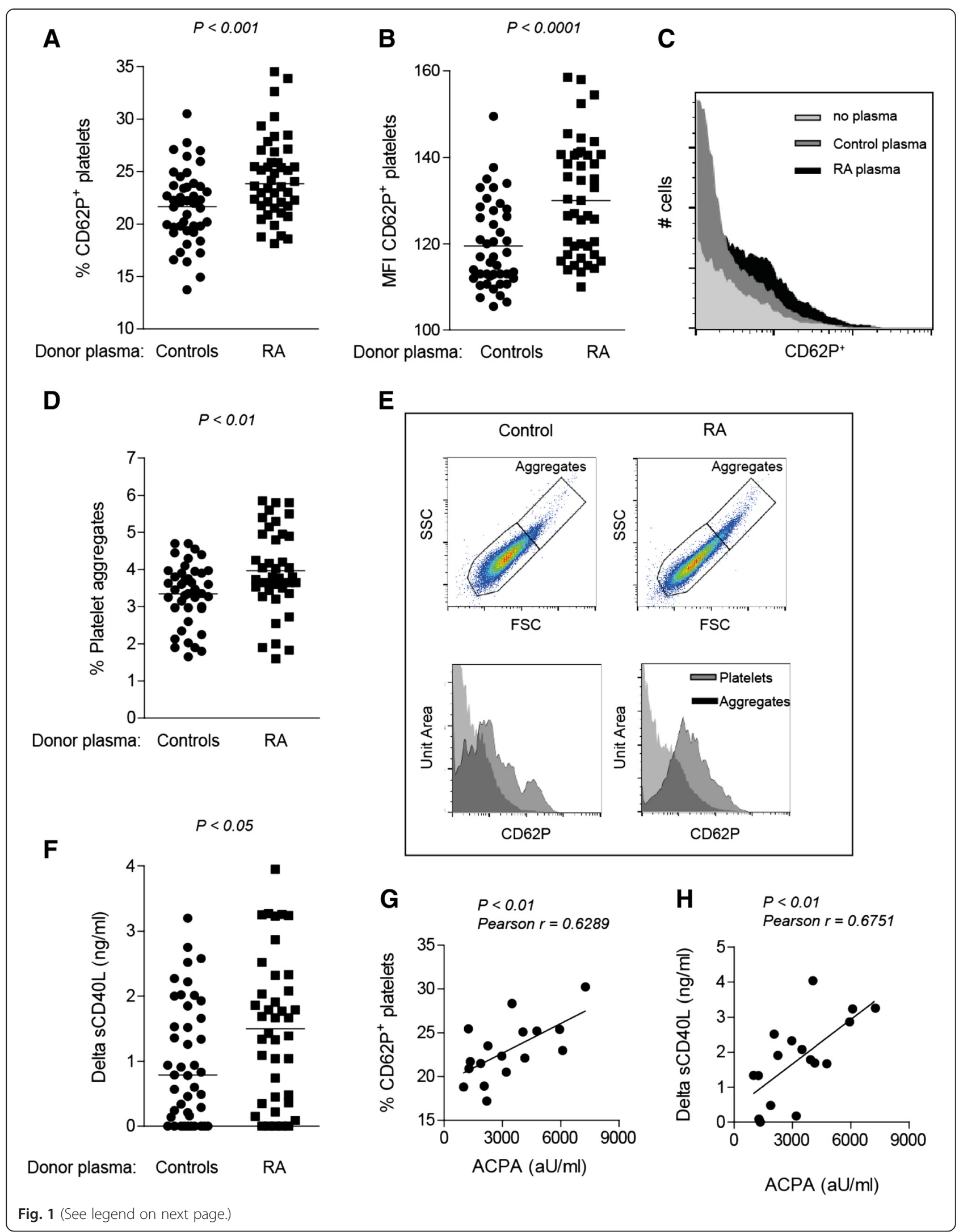


(See figure on previous page.)

Fig. 1 Plasma-derived factors enhance platelet activity. Platelets were isolated from buffy coat and incubated in the presence of plasma obtained from patients with rheumatoid arthritis (RA) or age- and sex-matched healthy controls (cohort 1). Plasma from patients with RA induced higher platelet activation than did plasma from healthy donors, as indicated by (a) increased percentage and (b) mean fluorescence intensity (MFI) of P-selectin (CD62P) expression, (d) platelet aggregation and (f) soluble CD40 ligand (sCD40L). c Histogram overlay showing representative examples of CD62P expression. e Representative pictures of aggregate formation and CD62P expression of non-aggregated and aggregated platelets. $\mathbf{f}$ Values of sCD40L were corrected for amounts present in plasma. Levels of (g) P-selectin and (h) sCD40L production correlated with high levels of anti-citrullinated protein antibodies (ACPA; > $1000 \mathrm{AU} / \mathrm{ml}$ ). Each symbol represents a plasma sample. FSC forward scatter, SSC side scatter

correlation between TNF- $\alpha$ and/or PAF with platelet characteristics (Additional file 2: Figure S2g-h) or disease activity (data not shown).

Because platelets express FcyRIIa, we next questioned if ACPA could potentially mediate the activation of platelets. Although we could not detect a correlation between ACPA and P-selectin expression on platelets in all patients with RA (Additional file 2: Figure S2a), we did observe a strong correlation between patients with higher ACPA levels ( $>1000 \mathrm{AU} / \mathrm{ml}$ ) and the expression of both P-selectin (Fig. 1g) (Pearson's $r=0.6289, P<0.01$ ) and the production of $\mathrm{sCD} 40 \mathrm{~L}$ by platelets (Fig. 1h) (Pearson's $r=0.6751, P<0.01)$. No correlation was observed between platelet characteristics and RF-IgM (Additional file 2: Figure S2e,f). These data indicate that platelet activation induced by a given plasma sample predicts group of the plasma donor (control vs patients with RA) and points towards an association between platelet activation and ACPA level.

\section{ACPA-mediated activation of platelets}

To further investigate the relationship between ACPA level and platelet activation, we incubated platelets from healthy subjects with plasma from either $\mathrm{ACPA}^{\text {neg }}$ or $\mathrm{ACPA}^{\text {pos }}$ patients with RA (cohort 2; age-, sex- and DAS44-matched). We again observed platelet activation when plasma from $\mathrm{ACPA}^{\text {pos }}$ patients was used as indicated by increased platelet P-selectin expression (Fig. 2a) (ACPA $^{\text {neg }}$ median 19.2, IQR 17.4-23.0; ACPA $^{\text {pos }}$ median 21.6, IQR 19.5-24.5; $P<0.05)$, increased CD62P MFI (Fig. 2b) $\left(\mathrm{ACPA}^{\text {neg }}\right.$ median 38.1, IQR 34.5-43.8; $\mathrm{ACPA}^{\text {pos }}$ median 46.2, IQR 39.5-52.9; $P<0.01)$ and increased number of platelet aggregates (Fig. 2d) $\left(\mathrm{ACPA}^{\text {neg }}\right.$ median 1.3, IQR 0.9-2.5; ACPA $^{\text {pos }}$ median 1.97, IQR 1.3-4.5; $\left.P<0.05\right)$. Like the observations in cohort 1 , a strong positive correlation was again seen between plasma samples with high
ACPA level and its ability to induce P-selectin expression on platelets from healthy subjects (Pearson's $r=0.7189$, $P<0.05)$ (Fig. 2f). To address the question whether ACPA could directly activate platelets, we coated plates with arginine- or citrulline-containing peptides and incubated the coated plates with plasma from $\mathrm{RF}^{\text {neg }} \mathrm{ACPA}^{\text {pos }}$ patients to generate platelet-bound ACPA-immune complexes. Plasma from $\mathrm{RF}^{\text {neg }} \mathrm{ACPA}^{\text {neg }}$ patients was used as a negative control. We observed a citrulline-dependent activation of platelets because neither the arginine control nor the use of $\mathrm{ACPA}^{\text {neg }}$ plasma resulted in increased Pselectin expression or sCD40L release (Fig. 3a-f). The ACPA-mediated activation of platelets was FcyRIIadependent because pre-incubation of platelets with antiCD32 inhibited upregulation of P-selectin expression and sCD40L release (Fig. 3g,h).

\section{Enhanced platelet activation correlates with disease activity}

In addition to increased P-selectin expression and sCD40L release, platelets transform from a normal discoid shape into a more spherical shape with protrusions of pseudopods during activation. This is visualised as increased MPV and enhanced PDW. As plasma from patients with RA is capable of inducing platelet activation, we next compared freshly isolated platelets from patients with RA with those of healthy controls. We observed a higher basal activation status of platelets isolated from patients with RA, as indicated by increased MPV, PDW, platelet numbers and expression of P-selectin (Table 3). Because there is variation in total IgG levels between patients, we corrected for the presence of IgG by isolating ACPA and calculating the percentage of ACPA to total IgG. The expression of P-selectin on platelets from patients with RA correlated with DAS44 (Pearson's $r=0.4708, P<0.05$ ), Creactive protein $(\mathrm{CRP})$ levels (Pearson's $r=0.4239, P<0.05$ )

Table 2 Linear regression analysis

\begin{tabular}{|c|c|c|c|c|c|c|c|}
\hline Dependent variable & $\beta$-coefficient & SEM & $t$ & $P$ value & $\beta$ & \multicolumn{2}{|c|}{$95 \% \mathrm{Cl}$} \\
\hline CD62P & 2.01 & 0.80 & 2.50 & 0.01 & 0.27 & 0.41 & 3.60 \\
\hline Aggregates & 0.47 & 0.24 & 1.96 & 0.05 & 0.21 & -0.01 & 0.95 \\
\hline sCD40L & 0.51 & 0.23 & 2.24 & 0.03 & 0.24 & 0.06 & 0.96 \\
\hline
\end{tabular}

CD62P P-selectin, $C l$ confidence interval, SCD40L soluble CD40 ligand, SEM standard error of the mean

The $\beta$-coefficient represents the effect sizes from the regression analyses of the association between platelet characteristics induced by a given plasma sample and group status of the plasma donor. $\beta$-values represent the standardised regression coefficients

The $t$ statistic $(t)$ is the beta-coefficient divided by its standard error 


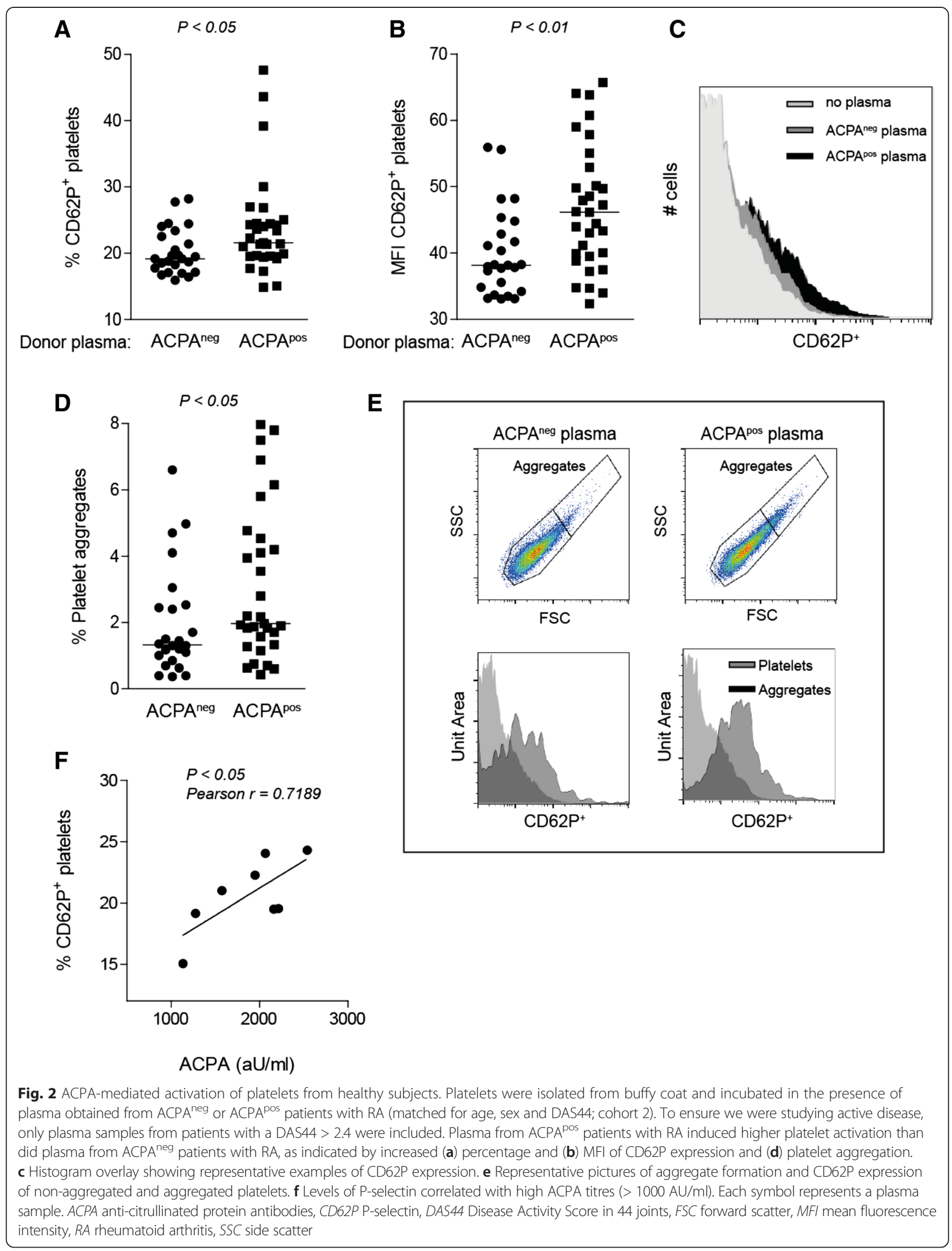




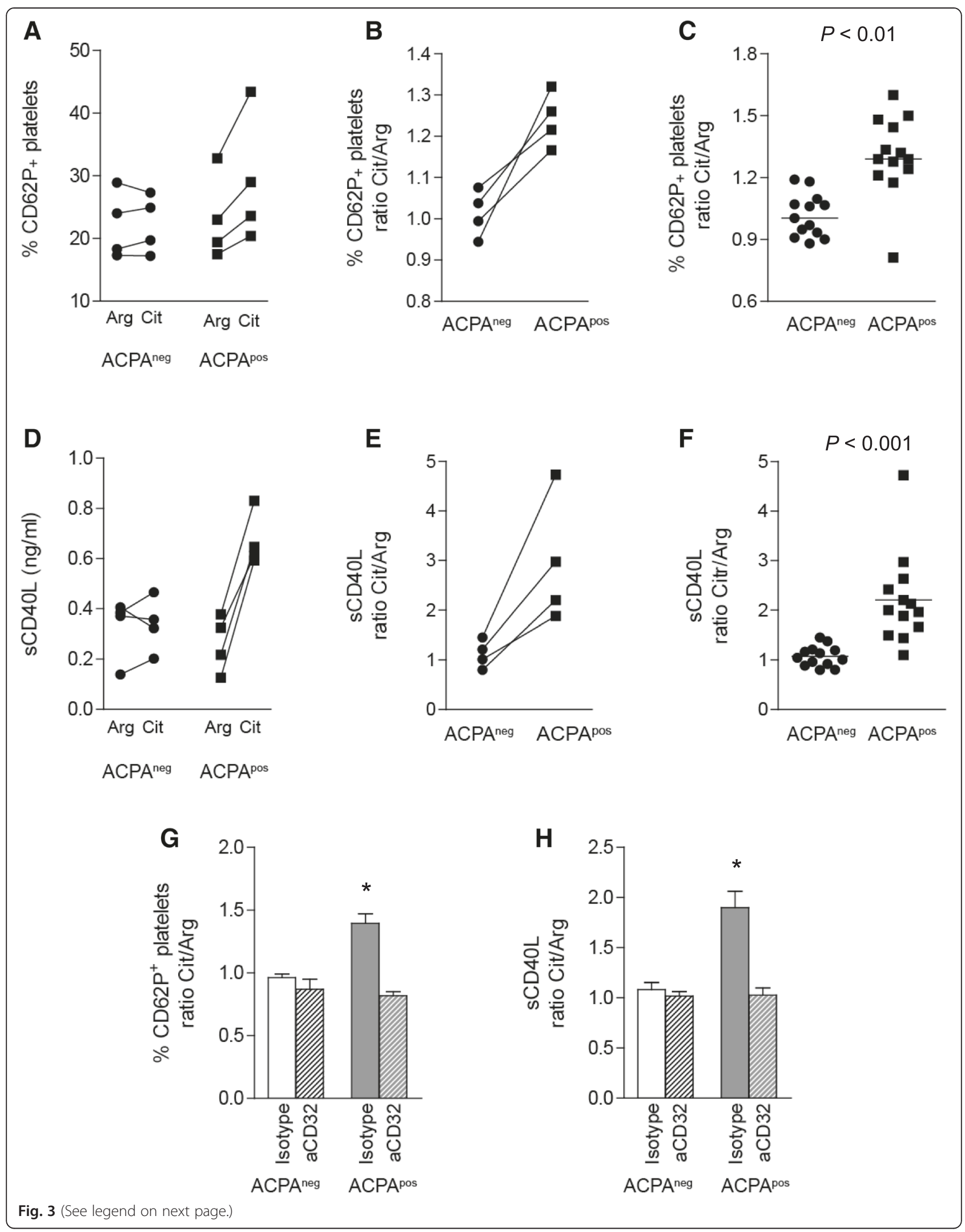


(See figure on previous page.)

Fig. 3 Citrulline-specific activation of platelets is FcyRlla-dependent. Platelets were isolated from healthy donors. ACPA plate-bound immune complexes were generated by incubating $\mathrm{ACPA}^{\text {neg }}$ and $\mathrm{ACPA}^{\text {pos }}$ plasma on wells coated with citrulline- or arginine-containing peptides. Representative examples of citrulline-specific increase in P-selectin expression and SCD40L release are shown in $\mathbf{a}$ and $\mathbf{d}$, respectively. $\mathbf{b}$ and $\mathbf{e}$ These effects are still present after correcting for aspecific binding by calculating the citrulline/arginine ratio. $\mathbf{c}$ and $\mathbf{f}$ Summaries of three independent experiments. Pre-incubation of platelets with a blocking antibody directed against FcyRlla abolished the citrulline-specific induction of P-selectin (g) and SCD40L release (h). ACPA anti-citrullinated protein antibodies, CD62P P-selectin, FcyRlla low-affinity immunoglobulin G receptor, SCD40L soluble CD40 ligand. ${ }^{*} \mathrm{P}<0.05$

and the percentage of ACPA (Pearson's $r=0.5497, P<0.01$ ) (Fig. 4a-c). In addition, the number of platelets also correlated with DAS44 (Pearson's $r=0.5150, P<0.01$ ), CRP (Pearson's $r=0.4240, \quad P<0.05)$ and percentage of ACPA (Pearson's $r=0.6183, P<0.001$ ) (Fig. $4 \mathrm{~d}-\mathrm{f}$ ). Together, these findings indicate enhanced platelet activation in patients with RA which correlates with disease activity and the presence of ACPA.

\section{Discussion}

Besides their well-established role in haemostasis and thrombin generation, ample data are now emerging on the immunoregulatory functions of platelets [1-3]. Platelets are closely involved in the initiation and/or perpetuation of inflammatory events and cellular influx taking place at the endothelium-synovium interface by releasing a large plethora of cytokines, chemokines and growth factors. Furthermore, recent data tend to support a relatively unexplored role for platelets during the inflammatory events of RA [13]. Initially, the involvement of platelets in joint inflammation was described in mice. Platelets were found to interact with and adhere to endothelial cells and leucocytes in the inflamed synovial vessels and also to contribute to the production of arthritogenic prostaglandins in the $\mathrm{K} / \mathrm{BxN}$ mouse model [39-41]. Furthermore, platelet depletion reduced vascular leakage in arthritic joints and attenuated inflammatory arthritis $[4,11,12]$. Now, data are emerging on platelet activation in patients with RA [15-19, 42].

Table 3 Characteristics isolated platelets from healthy controls vs patients with RA

\begin{tabular}{llll}
\hline & Healthy controls & Patients with RA & $P$ value \\
\hline Total number & 29 & 32 & \\
Female, $\mathrm{n}(\%)$ & $16(55.2)$ & $22(68.75)$ & \\
Male, $\mathrm{n}(\%)$ & $13(44.8)$ & $10(31.25)$ & \\
Age, yr & $37.4 \pm 1.79$ & $63.5 \pm 2.24$ & $<0.0001$ \\
$\begin{array}{l}\text { Mean platelet } \\
\text { volume (fl) }\end{array}$ & $7.88 \pm 0.137$ & $8.41 \pm 0.183$ & 0.0273 \\
$\begin{array}{l}\text { Platelet distribution } \\
\text { width (fl) }\end{array}$ & $9.71 \pm 0.217$ & $10.13 \pm 0.295$ & $\mathrm{~ns}$ \\
$\begin{array}{l}\text { Platelet numbers } \\
\left(10^{9} / \mathrm{L}\right)\end{array}$ & $298.3 \pm 21.29$ & $383.9 \pm 28.66$ & 0.0187 \\
$\begin{array}{l}\text { P-selectin } \\
\text { expression (\%) }\end{array}$ & $17.94 \pm 1.188$ & $44.28 \pm 1.889$ & $<0.0001$ \\
$\begin{array}{l}\text { ns not significant } \\
\text { n non }\end{array}$ & & &
\end{tabular}

ns not significant
Studying the phenotype of freshly isolated platelets from patients with RA, we indeed observed an increased activation status, as indicated by the MPV, platelet numbers and P-selectin expression of patients with RA compared with healthy controls. MPV increase during aging, which is still debated, could represent a limitation of these findings, as these groups were not matched for age [43, 44]. However, among the patients with RA, we observed a correlation between P-selectin expression and DAS44, CRP and the percentage ACPA to total IgG, confirming and extending the correlation between activation of platelets and disease activity [45]. Treatment of patients with RA included a wide variety of DMARDs, biologic agents and glucocorticoids. Over time, several patients received different forms of medication or even a combination of drugs. The effect of anti-arthritis medications on bloodrelated prothrombotic and proinflammatory parameters has been reviewed by Beinsberger et al. [46], who compared conventional therapy with methotrexate and antiTNF treatment and showed that anti-arthritis medications have a normalising effect on blood-related prothrombotic and proinflammatory parameters. Furthermore, sulphasalazine inhibits arachidonic acid-induced platelet aggregation similarly to the way aspirin and hydroxychloroquine reverse platelet activation induced by human IgG antiphospholipid antibodies $[47,48]$. Together, these data indicate that anti-rheumatic treatment actually reduces platelet activation and therefore is unlikely to have contributed to the increased platelet activation observed in our study.

Previous studies indicated that platelets from patients with RA express higher P-selectin levels and produce higher amounts of sCD40L $[15,42]$. In the present study, we show that incubation of platelets from healthy subjects with plasma derived from patients with RA induces an activated platelet phenotype, as indicated by elevated P-selectin expression, increased sCD40L production and enhanced aggregation. This indicates that RA plasma-derived factors can induce platelet activation. PAF and TNF- $\alpha$ are important mediators in RA that are known to be involved in the activation of platelets $[38,49,50]$. We indeed observed elevated levels of both PAF and TNF- $\alpha$ in plasma of patients with RA, but we could not find a correlation with platelet characteristics. As platelets express only FcyRIIA, which is known for binding IgG immune complexes, we hypothesised that the presence of immune complexes containing autoantibodies 

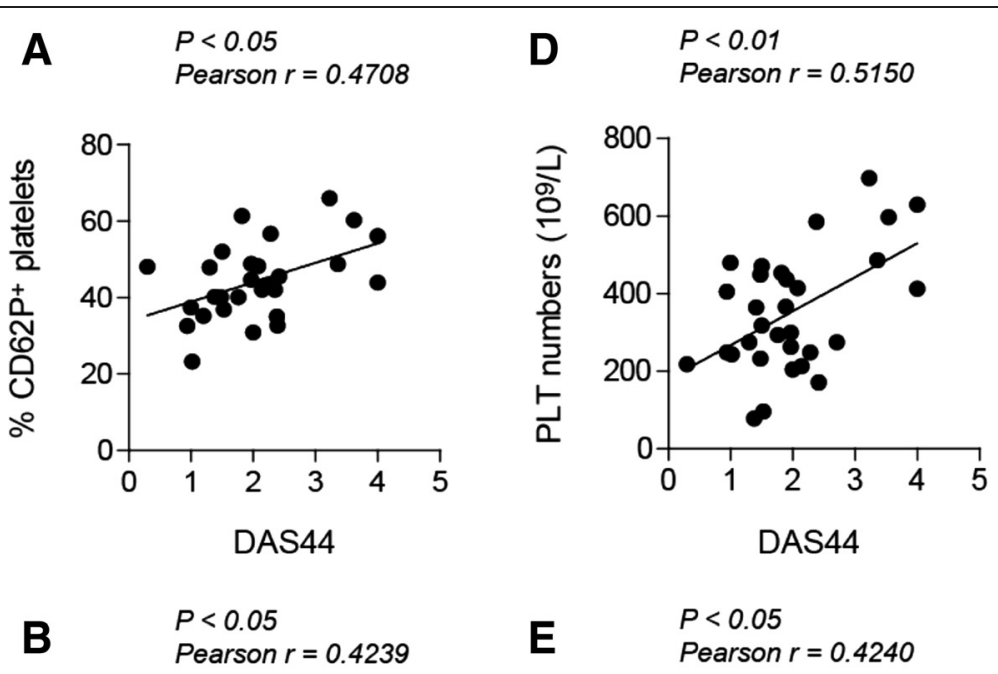

$$
\text { E } \quad \begin{aligned}
& P<0.05 \\
& P \text { earson } r=0.4240
\end{aligned}
$$
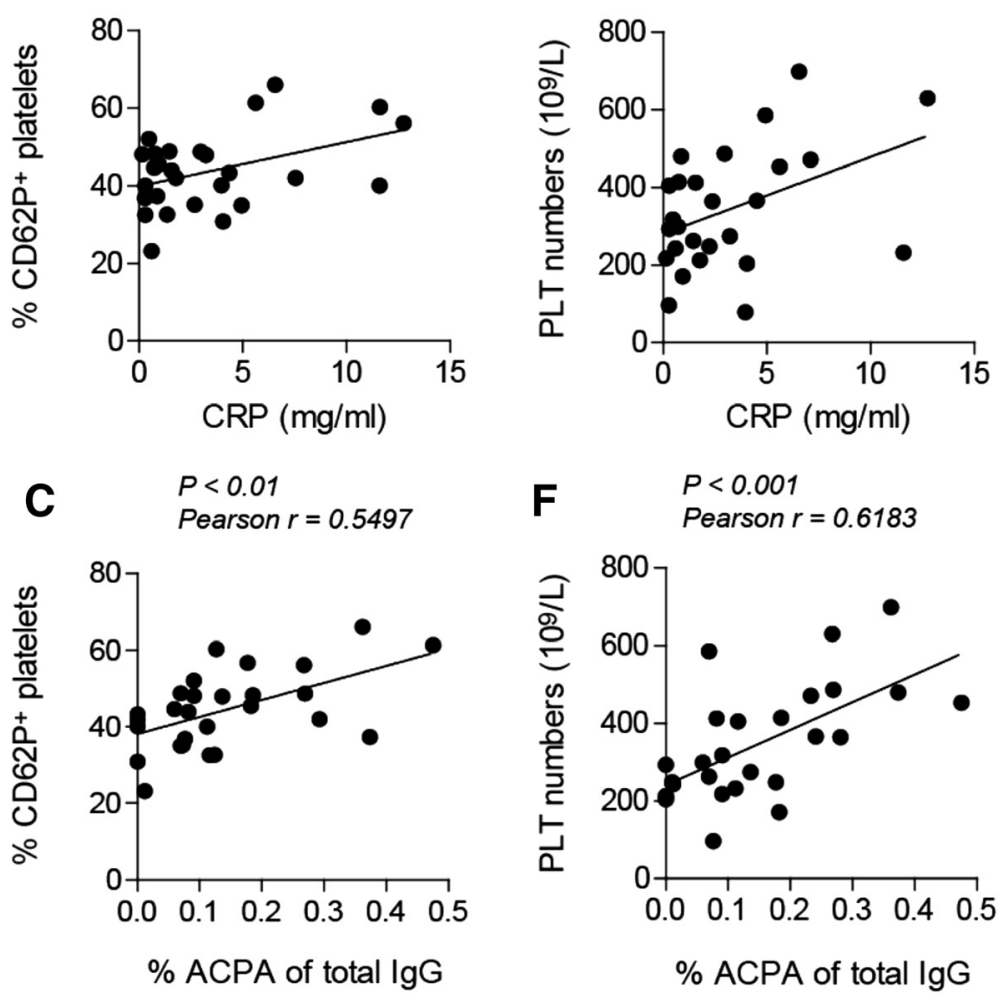

Fig. 4 Platelet phenotype correlates with disease activity. The expression of P-selectin (CD62P) was determined on isolated platelets from patients with rheumatoid arthritis (RA) and correlated with Disease Activity Score in 44 joints (DAS44) (a), C-reactive protein (CRP) levels (b) and anti-citrullinated protein antibodies (ACPA) (c). Platelet (PLT) numbers correlated with DAS44 score (d), CRP levels (e) and ACPA levels (f). lgG immunoglobulin G

could mediate platelet activity [51]. Interestingly, in platelet aggregometry studies done many years ago, researchers identified IgG-containing immune complexes as potential triggers for excessive platelet aggregation [52, 53]. Furthermore, IgG immune complexes collected from the serum of patients with systemic lupus erythematosus were shown to activate healthy platelets and that blocking the FcyRIIa receptor or depleting the serum of immunoglobulins abolished the increased platelet activation [54]. Moreover, exposure to complexed IgG increases the sensitivity towards low doses of thrombin, which could result in accelerated vascular complications in vivo [55]. Our studies show the involvement of Fc $\gamma$ RIIA in mediating platelet activation in the presence ACPA.

We describe a strong correlation between high ACPA levels and platelet characteristics and show that platelets 
can be activated by plate-bound ACPA. Recently, it became apparent that human platelets do not express the IgM Fc receptor, making it unlikely that platelets become activated in the presence of IgM-containing immune complexes [56]. Indeed, in our present study, we did not observe a correlation between RF-IgM and platelet activation. Notably, these data are in accordance with the observations of Scott et al., who found no correlation between platelet aggregation and IgM-RF or IgG-RF in patients with RA [57].

ACPA-mediated activation of platelets is potentially of relevance for the earliest phases of RA because, during vascular injury, a tripartite interaction between the damaged endothelium, platelets and neutrophils develops. Wipke et al. elegantly showed that, within minutes of intravenous injection, autoantibodies specifically localise to joints destined to become inflamed in the $\mathrm{K} / \mathrm{BxN}$ mouse model of RA, even in the absence of pre-existing joint inflammation [58]. Furthermore, the formation of immune complexes on the articular surface initiates an inflammatory cascade leading to increased vascular permeability [59]. The specific homing of autoantibodies to the joints could contribute to local activation of platelets, which in turn release important mediators of vascular permeability, such as IL-1 and serotonin $[4,11]$. Importantly, patients with RA have an increased mortality risk ( $50 \%$ higher) relative to the healthy population, which is largely attributable to increased cardiovascular disease (CVD), particularly atherosclerosis. As endothelial dysfunction is the initiating step in atherosclerosis, and because of the prominent role of platelets during CVD, it could well be that ACPA-mediated activation of platelets contributes to CVD in patients with RA. Indeed, seropositivity for RF and ACPA is associated with increased CVD risk in patients with RA and is related to impaired endothelial function [30-32, 34]. Remarkably, Cambridge et al. recently described an association between anti-CCP antibodies and coronary heart disease even in the absence of rheumatic disease [26].

\section{Conclusions}

Although several factors are at play in influencing platelets during established RA, we believe that, especially in the initiating (symptom-free) phase of the disease, ACPA-mediated activation of platelets could have an important role in enhancing the basal activation status of platelets, as ACPA can be detected many years before disease onset. Because platelets carry various mediators facilitating the recruitment of circulating monocytes and/or leucocytes to injured endothelium and have the potential to propagate vascular permeability, this ACPA-mediated activation of platelets could be the initialising step of the enhanced erosive damage observed in $\mathrm{ACPA}^{\text {pos }}$ patients and/or the increased cardiovascular risk. Unfortunately, we had no access to a prospective cohort in which the platelet phenotype of healthy blood donors who in time develop RA was monitored. To confirm our hypothesis, it would be of great interest to investigate whether the occurrence of ACPA coincides with platelet activation in patients with clinically silent RA.

\section{Additional files}

Additional file 1: Figure S1. Visualisation of thrombin receptor-activating peptide (TRAP)-mediated platelet aggregation using flow cytometry. Platelets from healthy donors were isolated and incubated in the presence of TRAP $(0,0.5$ or $5 \mu \mathrm{M}$ TRAP), and the formation of platelet aggregates was analysed. Histograms showing the P-selectin upregulation upon TRAP activation for non-aggregated platelets (filled histograms) and aggregated platelets (open histograms) (a). Correlation between percentage aggregates measured by flow cytometry and P-selectin expression after activation in the presence of all plasma samples of cohort 1. Each symbol represents a plasma sample (b). (PDF 78 kb)

Additional file 2: Figure S2. Correlations between platelet activation and markers of inflammation. Correlation between percentage P-selectin expression in all patients (a) and patients with ACPA > $1000 \mathrm{AU} / \mathrm{ml}$ (b). Correlation between SCD40L in all patients (c) and patients with $\mathrm{ACPA}>1000 \mathrm{AU} / \mathrm{ml}$ (d). Correlation between percentage P-selectin expression and RF-IgM in all patients (e) and patients with RF-IgM $>50$ $\mathrm{IU} / \mathrm{ml}(\mathbf{f})$. Correlation between TNF-a and P-selectin expression in all patients $(\mathbf{g})$. Correlation between PAF and P-selectin expression in all patients (h). Each symbol represents a plasma sample. (PDF 67 kb)

\section{Abbreviations}

ACPA: Anti-citrullinated protein antibodies; CCP: Cyclic citrullinated peptide; CD62P: P-selectin; Cl: Confidence interval; CRP: C-reactive protein; CVD: Cardiovascular disease; DAS: Disease Activity Score; DMARD: Diseasemodifying antirheumatic drug; ELISA: Enzyme-linked immunosorbent assay; FcyRlla: Low-affinity immunoglobulin G receptor; FSC: Forward scatter; HEPES: 2-[4-(2-hydroxyethyl)piperazin-1-yl]ethanesulfonic acid; IgG: Immunoglobulin G; IL: Interleukin; IQR: Interquartile range; MFI: Mean fluorescence intensity; MPV: Mean platelet volume; PAF: Platelet-activating factor; PBS: Phosphate-buffered saline; PDW: Platelet distribution width; PLT: Platelets; RA: Rheumatoid arthritis; RF: Rheumatoid factor; RT: Room temperature; sCD40L: Soluble CD40 ligand; SEM: Standard error of the mean; SSC: Side scatter; TNF: Tumour necrosis factor.

\section{Competing interests}

The authors declare that they have no competing interests.

\section{Authors' contributions}

KLLH designed the study, performed experiments, analysed and interpreted data and drafted the manuscript. LAT and EWNL designed and performed experiments, analysed and interpreted data in order to describe the cohorts 1 and 2 in Table 1 , and critically revised the manuscript. PAMH performed statistical analysis, interpreted data and has critically revised the manuscript. SJAK participated in experiments regarding platelet isolation and activation, analysed and interpreted data and has critically revised the manuscript. PdG interpreted data regarding platelet activation and has critically revised the manuscript. TWJH and REMT participated in the design of the study, interpreted data and have critically revised the manuscript. All authors read and approved the final version of the manuscript.

\section{Acknowledgements}

We thank Priscilla Kerkman and Lise Hafkenscheid of the Department Rheumatology, Leiden University Medical Centre, Leiden, the Netherlands, for optimising and performing the procedures to purify ACPA-IgG using CCP-2-coated beads. The research leading to the reported results was supported by European Community Innovative Medicines Initiative joint undertaking BeTheCure under grant agreement 115142, the European 
Commission FP7 Health programme under grant agreement FP7-HEALTHF2-2012-305549, the Landsteiner Foundation for Blood Transfusion Research under grant 0912F, and the Dutch Arthritis Foundation.

\section{Author details}

'Department of Rheumatology, Leiden University Medical Centre, C1-R, PO Box 9600, 2300 RC, Leiden, the Netherlands. 'Department of Clinical Chemistry and Haematology, University Medical Centre, Utrecht, the Netherlands. ${ }^{3}$ Division of Biopharmaceutics, Leiden Amsterdam Centre for Drug Research, University of Leiden, Leiden, the Netherlands. ${ }^{4}$ Knowledge Centre Forensic Psychiatric Care, Rekem Psychiatric Hospital, Rekem, Belgium.

Received: 16 December 2014 Accepted: 29 May 2015

Published online: 24 August 2015

\section{References}

1. Gasparyan AY. Platelets in inflammation and thrombosis. Inflamm Allergy Drug Targets. 2010;9:319-21.

2. Habets KL, Huizinga TW, Toes RE. Platelets and autoimmunity. Eur J Clin Invest. 2013:43:746-57.

3. Nurden AT. Platelets, inflammation and tissue regeneration. Thromb Haemost. 2011;105:S13-33.

4. Cloutier N, Paré A, Farndale RW, Schumacher HR, Nigrovic PA, Lacroix S, et al. Platelets can enhance vascular permeability. Blood. 2012;120:1334-43.

5. Huo Y, Ley KF. Role of platelets in the development of atherosclerosis. Trends Cardiovasc Med. 2004;14:18-22.

6. Projahn D, Koenen RR. Platelets: key players in vascular inflammation. J Leukoc Biol. 2012;92:1167-75.

7. Henn V, Slupsky JR, Gräfe M, Anagnostopoulos I, Förster R, Müller-Berghaus G, et al. CD40 ligand on activated platelets triggers an inflammatory reaction of endothelial cells. Nature. 1998;391:591-4.

8. Semple JW, Italiano Jr JE, Freedman J. Platelets and the immune continuum. Nat Rev Immunol. 2011;11:264-74.

9. Scott DL, Wolfe F, Huizinga TW. Rheumatoid arthritis. Lancet. 2010;376:1094-108.

10. FitzGerald O, Soden M, Yanni G, Robinson R, Bresnihan B. Morphometric analysis of blood vessels in synovial membranes obtained from clinically affected and unaffected knee joints of patients with rheumatoid arthritis. Ann Rheum Dis. 1991;50:792-6.

11. Boilard E, Nigrovic PA, Larabee K, Watts GF, Coblyn JS, Weinblatt ME, et al. Platelets amplify inflammation in arthritis via collagen-dependent microparticle production. Science. 2010;327:580-3.

12. Mott PJ, Lazarus AH. CD44 antibodies and immune thrombocytopenia in the amelioration of murine inflammatory arthritis. PLoS One. 2013;8:e65805.

13. Gasparyan AY, Ayvazyan L, Pretorius E, Kitas GD. Platelets in rheumatic diseases: friend or foe? Curr Pharm Des. 2014;20:552-66.

14. Knijff-Dutmer EA, Koerts J, Nieuwland R, Kalsbeek-Batenburg EM, van de Laar MA. Elevated levels of platelet microparticles are associated with disease activity in rheumatoid arthritis. Arthritis Rheum. 2002;46:1498-503.

15. Pamuk GE, Vural O, Turgut B, Demir M, Pamuk ON, Cakir N. Increased platelet activation markers in rheumatoid arthritis: are they related with subclinical atherosclerosis? Platelets. 2008;19:146-54.

16. Cheng T, Li FF, Zhao S, Peng XC, Zhang XL. Soluble P selectin in synovial fluid level is correlated with the radiographic severity of knee osteoarthritis. Clin Chim Acta. 2010;411:1529-31.

17. Ertenli I, Kiraz S, Arici M, Haznedaroglu IC, Calgüneri M, Celik I, et al. P-selectin as a circulating molecular marker in rheumatoid arthritis with thrombocytosis. J Rheumatol. 1998:25:1054-8.

18. Prahalad S, Martins TB, Tebo AE, Whiting A, Clifford B, Zeft AS, et al. Elevated serum levels of soluble CD154 in children with juvenile idiopathic arthritis. Pediatr Rheumatol Online J. 2008;6:8.

19. Tamura N, Kobayashi S, Kato K, Bando H, Haruta K, Oyanagi M, et al. Soluble CD154 in rheumatoid arthritis: elevated plasma levels in cases with vasculitis. J Rheumatol. 2001;28:2583-90.

20. Chung WS, Peng CL, Lin CL, Chang YJ, Chen YF, Chiang JY, et al. Rheumatoid arthritis increases the risk of deep vein thrombosis and pulmonary thromboembolism: a nationwide cohort study. Ann Rheum Dis. 2014;73:1774-80.

21. Holmqvist ME, Neovius M, Eriksson J, Mantel Ä, Wållberg-Jonsson S, Jacobsson LT, et al. Risk of venous thromboembolism in patients with rheumatoid arthritis and association with disease duration and hospitalization. JAMA. 2012;308:1350-6.

22. Gustafsson JT, Simard JF, Gunnarsson I, Elvin K, Lundberg IE, Hansson LO, et al. Risk factors for cardiovascular mortality in patients with systemic lupus erythematosus, a prospective cohort study. Arthritis Res Ther. 2012;14:R46.

23. Nishimura K, Sugiyama D, Kogata Y, Tsuji G, Nakazawa T, Kawano S, et al. Meta-analysis: diagnostic accuracy of anti-cyclic citrullinated peptide antibody and rheumatoid factor for rheumatoid arthritis. Ann Intern Med. 2007;146:797-808.

24. van der Helm-van Mil AH, Verpoort KN, Breedveld FC, Toes RE, Huizinga TW. Antibodies to citrullinated proteins and differences in clinical progression of rheumatoid arthritis. Arthritis Res Ther. 2005;7:R949-58.

25. van Gaalen FA, Linn-Rasker SP, van Venrooij WJ, de Jong BA, Breedveld FC,

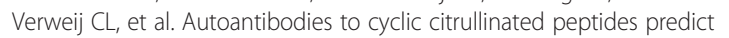
progression to rheumatoid arthritis in patients with undifferentiated arthritis: a prospective cohort study. Arthritis Rheum. 2004;50:709-15.

26. Cambridge G, Acharya J, Cooper JA, Edwards JC, Humphries SE. Antibodies to citrullinated peptides and risk of coronary heart disease. Atherosclerosis. 2013;228:243-6.

27. El-Barbary AM, Kassem EM, El-Sergany MA, Essa SA, Eltomey MA. Association of anti-modified citrullinated vimentin with subclinical atherosclerosis in early rheumatoid arthritis compared with anti-cyclic citrullinated peptide. J Rheumatol. 2011;38:828-34.

28. Gerli R, Bartoloni Bocci E, Sherer Y, Vaudo G, Moscatelli S, Shoenfeld Y. Association of anti-cyclic citrullinated peptide antibodies with subclinical atherosclerosis in patients with rheumatoid arthritis. Ann Rheum Dis. 2008:67:724-5.

29. Giles JT, Fert-Bober J, Park JK, Bingham 3rd CO, Andrade F, Fox-Talbot K, et al. Myocardial citrullination in rheumatoid arthritis: a correlative histopathologic study. Arthritis Res Ther. 2012;14:R39.

30. Goodson NJ, Wiles NJ, Lunt M, Barrett EM, Silman AJ, Symmons DP. Mortality in early inflammatory polyarthritis: cardiovascular mortality is increased in seropositive patients. Arthritis Rheum. 2002;46:2010-9.

31. Hjeltnes G, Hollan I, Forre O, Wiik A, Mikkelsen K, Agewall S. Anti-CCP and RF IgM: predictors of impaired endothelial function in rheumatoid arthritis patients. Scand J Rheumatol. 2011;40:422-7.

32. López-Longo FJ, Oliver-Miñarro D, de la Torre I, González-Díaz de Rábago E, Sánchez-Ramón S, Rodríguez-Mahou M, et al. Association between anticyclic citrullinated peptide antibodies and ischemic heart disease in patients with rheumatoid arthritis. Arthritis Rheum. 2009;61:419-24.

33. Maradit-Kremers H, Nicola PJ, Crowson CS, Ballman KV, Gabriel SE. Cardiovascular death in rheumatoid arthritis: a population-based study. Arthritis Rheum. 2005;52:722-32.

34. Tomasson G, Aspelund T, Jonsson T, Valdimarsson H, Felson DT, Gudnason $V$. Effect of rheumatoid factor on mortality and coronary heart disease. Ann Rheum Dis. 2010;69:1649-54.

35. Arnett FC, Edworthy SM, Bloch DA, McShane DJ, Fries JF, Cooper NS, et al. The American Rheumatism Association 1987 revised criteria for the classification of rheumatoid arthritis. Arthritis Rheum. 1988;31:315-24.

36. Vergeer M, Korporaal SJ, Franssen R, Meurs I, Out R, Hovingh GK, et al. Genetic variant of the scavenger receptor Bl in humans. N Engl J Med. 2011;364:136-45.

37. Matzdorff AC, Kühnel G, Kemkes-Matthes B, Pralle H. Quantitative assessment of platelets, platelet microparticles, and platelet aggregates with flow cytometry. J Lab Clin Med. 1998;131:507-17.

38. Pignatelli $P$, De Biase L, Lenti L, Tocci G, Brunelli A, Cangemi R, et al. Tumor necrosis factor-a as trigger of platelet activation in patients with heart failure. Blood. 2005;106:1992-4.

39. Boilard E, Larabee K, Shnayder R, Jacobs K, Farndale RW, Ware J, et al. Platelets participate in synovitis via Cox-1-dependent synthesis of prostacyclin independently of microparticle generation. J Immunol. 2011;186:4361-6.

40. Schmitt-Sody M, Klose A, Gottschalk O, Metz P, Gebhard H, Zysk S, et al. Platelet-endothelial cell interactions in murine antigen-induced arthritis. Rheumatology (Oxford). 2005;44:885-9.

41. Schmitt-Sody M, Metz P, Gottschalk O, Birkenmaier C, Zysk S, Veihelmann A, et al. Platelet P-selectin is significantly involved in leukocyte-endothelial cell interaction in murine antigen-induced arthritis. Platelets. 2007;18:365-72.

42. Wang F, Wang NS, Yan CG, Li JH, Tang LQ. The significance of platelet activation in rheumatoid arthritis. Clin Rheumatol. 2007;26:768-71.

43. Demirin H, Ozhan H, Ucgun T, Celer A, Bulur S, Cil H, et al. Normal range of mean platelet volume in healthy subjects: Insight from a large epidemiologic study. Thromb Res. 2011;128:358-60. 
44. Lippi G, Meschi T, Borghi L. Mean platelet volume increases with aging in a large population study. Thromb Res. 2012;129:e159-60.

45. Yazici S, Yazici M, Erer B, Calik Y, Ozhan H, Ataoglu S. The platelet indices in patients with rheumatoid arthritis: mean platelet volume reflects disease activity. Platelets. 2010;21:122-5.

46. Beinsberger J, Heemskerk JW, Cosemans JM. Chronic arthritis and cardiovascular disease: altered blood parameters give rise to a prothrombotic propensity. Semin Arthritis Rheum. 2014;44:345-52.

47. Espinola RG, Pierangeli SS, Gharavi AE, Harris EN. Hydroxychloroquine reverses platelet activation induced by human IgG antiphospholipid antibodies. Thromb Haemost. 2002:87:518-22.

48. Yazici S, Yazici M, Erer B, Calik Y, Bulur S, Ozhan H, et al. The platelet functions in patients with ankylosing spondylitis: anti-TNF-a therapy decreases the mean platelet volume and platelet mass. Platelets. 2010;21:126-31.

49. Miguélez R, Palacios I, Navarro F, Gutierrez S, Sanchez-Pernaute O, Egido J, et al. Anti-inflammatory effect of a PAF receptor antagonist and a new molecule with antiproteinase activity in an experimental model of acute urate crystal arthritis. J Lipid Mediat Cell Signal. 1996;13:35-49.

50. Pignatelli P, Cangemi R, Celestini A, Carnevale R, Polimeni L, Martini A, et al. Tumour necrosis factor a upregulates platelet CD40L in patients with heart failure. Cardiovasc Res. 2008;78:515-22.

51. King $M$, McDermott $P$, Schreiber AD. Characterization of the Fcy receptor on human platelets. Cell Immunol. 1990;128:462-79.

52. Falus A, Merétey K, Bagdy D, Diószegi M, Böhm U, Csák E, et al. $\beta$-2microglobulin-specific autoantibodies cause platelet aggregation and interfere with ADP-induced aggregation. Clin Exp Immunol. 1982;47:103-9.

53. Fink PC, Piening U, Fricke PM, Deicher H. Platelet aggregation and aggregation inhibition by different antiglobulins and antiglobulin complexes from sera of patients with rheumatoid arthritis. Arthritis Rheum. 1979;22:896-903.

54. Duffau P, Seneschal J, Nicco C, Richez C, Lazaro E, Douchet I, et al. Platelet CD154 potentiates interferon-a secretion by plasmacytoid dendritic cells in systemic lupus erythematosus. Sci Transl Med. 2010;2:47ra63.

55. Berlacher MD, Vieth JA, Heflin BC, Gay SR, Antczak AJ, Tasma BE, et al. FcyRlla ligation induces platelet hypersensitivity to thrombotic stimuli. Am J Pathol. 2013;182:244-54.

56. Kubagawa H, Oka S, Kubagawa Y, Torii I, Takayama E, Kang DW, et al. Identity of the elusive IgM Fc receptor (Fc $\mu R)$ in humans. J Exp Med. 2009;206:2779-93.

57. Scott DG, Bacon PA, Allen C, Elson CJ, Wallington T. IgG rheumatoid factor, complement and immune complexes in rheumatoid synovitis and vasculitis: comparative and serial studies during cytotoxic therapy. Clin Exp Immunol. 1981;43:54-63.

58. Wipke BT, Wang Z, Kim J, McCarthy TJ, Allen PM. Dynamic visualization of a joint-specific autoimmune response through positron emission tomography. Nat Immunol. 2002;3:366-72.

59. Matsumoto I, Maccioni M, Lee DM, Maurice M, Simmons B, Brenner M, et al. How antibodies to a ubiquitous cytoplasmic enzyme may provoke joint-specific autoimmune disease. Nat Immunol. 2002;3:360-5.

\section{Submit your next manuscript to BioMed Central and take full advantage of:}

- Convenient online submission

- Thorough peer review

- No space constraints or color figure charges

- Immediate publication on acceptance

- Inclusion in PubMed, CAS, Scopus and Google Scholar

- Research which is freely available for redistribution

Submit your manuscript at www.biomedcentral.com/submit 